\title{
Cook Me and Call Me the Molecular Dice!
}

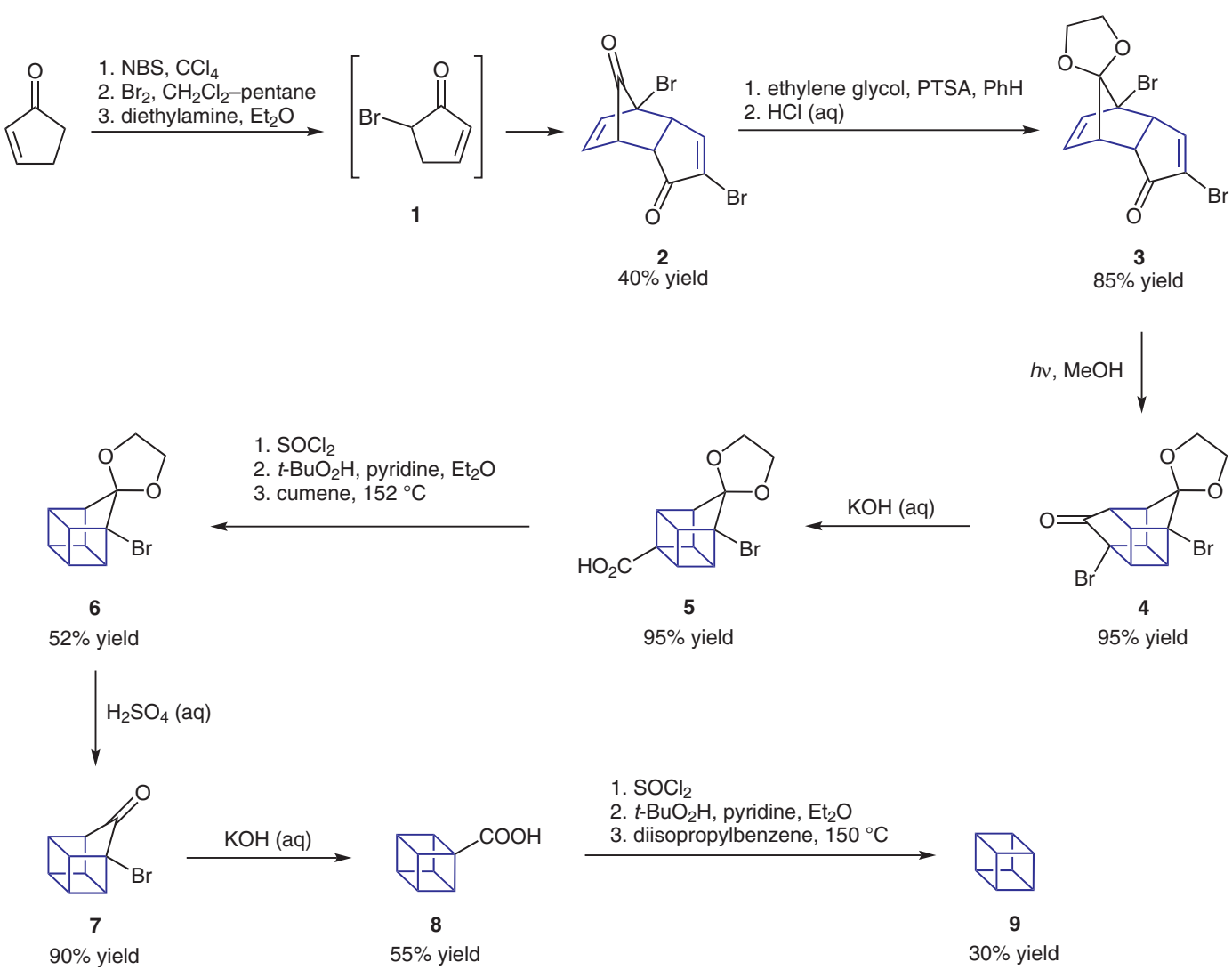

\section{Key words}

cubanes

hydrocarbons

strained structures
Significance: Cubane (9) is a highly strained hydrocarbon in which eight carbon atoms are arranged at the corners of a cube, adopting unusually $90^{\circ}$ bonding angles. Before it was first synthesized in 1964 by Eaton and Cole, researchers believed that such cubic carbon-based molecule would be too unstable to exist. Initially, cubane was considered just a laboratory curiosity of interest only to academics, however, over time this remarkable hydrocarbon and derivatives have found applications in controlled energy storage, the explosives industry, pharmaceuticals, and polymer science.
Comment: The classic synthesis of cubane starts from 2-cyclopentenone and consists of fifteen discrete steps with an overall yield of about $5 \%$. There are three key synthetic elements: (a) the highly endo-selective Diels-Alder reaction of 2-bromocyclopentadienone (1) generated in situ, producing the endo-dimer 2 (J. Am. Chem. Soc.1964, 86, 962); (b) the [2+2] photocyclization of 3, obtaining 4; and (c) the double Favorskii ring contraction of the cage diones $\mathbf{4}$ and $\mathbf{7}$, producing 5 and $\mathbf{8}$, respectively. Nowadays, the chemistry of cubane is well developed and it can be easily obtained on a multi-gram scale (see Review below).

Review: K. F. Biegasiewicz, J. R. Griffiths, G. P. Savage, J. Tsanaktsidis, R. Priefer Chem. Rev. 2015, 115, 6719-6745. 